\title{
Mineração
}

\section{Utilização de variável mineralógica na estimativa de reservas de minério de ferro}

\author{
Walmir Carvalho Pereira \\ Eng. Chefe do Depto. de Planejamento de Mina, MSc - Samarco Mineração S.A. \\ E-mail:walmir@samarco.com.br \\ Armando Zaupa Remacre \\ Prof. Dr., Instituto de Geociências - UNICAMP \\ E-mail: armando@ige.unicamp.br
}

\section{Resumo}

Nesse trabalho é apresentada uma metodologia para estimativa de reservas de minério de ferro, utilizando dados mineralógicos representados pelo mineral hematita especular. Os métodos geoestatísticos de simulação condicional e de estimativa por krigagem são usados para caracterizar a hematita especular em modelos de blocos. Teores de corte e reservas recuperáveis são determinados pelas funções de recuperação teor médio e tonelagem de minério. Os resultados mostraram diferenças significativas entre os modelos de krigagem e de simulação condicional.

Palavras-chave: simulação condicional, krigagem, reservas recuperáveis, funções de recuperação.

\begin{abstract}
This work presents a methodology to estimate iron ore reserves, which uses mineralogical data represented by the mineral specular hematite. The geostatistical methods of conditional simulation and kriging are used to characterize the specular hematite in block models. Cut-off grades and recoverable reserves are determined by using the recovery functions average grade and ore tonnage. The results showed significant differences between the kriged and the conditional simulation models.
\end{abstract}

Keywords: conditional simulation, kriging, recoverable reserves, recovery functions. 


\section{Introdução}

A composição mineralógica é a principal condicionante do comportamento dos minérios nas etapas dos processos de mineração e de siderurgia. Entre os minerais de ferro, a hematita especular é um dos minerais-minérios que contribui para a melhoria das qualidades físicas das pelotas de minério de ferro e, por conseqüência, influencia a produtividade da pelotização e o manuseio subseqüente das pelotas. Essa influência no desempenho dos processos industriais e nas propriedades físicas dos produtos de minério de ferro justifica a utilização da variável teor de hematita especular (He) na estimativa de reservas de minério de ferro,que é o objetivo desse trabalho.

\section{Metodologia}

A metodologia empregada consistiu em:

1. Implementação dos modelos de estimativa e de simulação geoestatística da variável He em blocos de lavra.

2. Seleção de teores de corte através das curvas da função de recuperação teor médio e estimativa de reservas através das curvas da função de recuperação tonelagem de minério.

\section{Dados gerais da área em estudo}

A área em estudo está localizada em uma região específica da mina de Alegria, de propriedade da Samarco Mine- ração S.A., que é uma empresa produtora e exportadora de pelotas de minério de ferro. Suas reservas minerais situamse no chamado Complexo Alegria, localizado na porção leste do Quadrilátero Ferrífero. Os processos de beneficiamento e pelotização da Samarco, embora tenham flexibilidade para absorver variações nas características mineralógicas do minério, estão normalmente ajustados para receber minérios cujo teor médio de He seja de $47 \%$ em volume de mineral (Pereira, 2003).

\section{Banco de dados e localização das informações de He}

Os dados utilizados nesse estudo são provenientes de análises mineralógicas de testemunhos de sondagem regularizados em $8 \mathrm{~m}$ de furos de sonda rotativos verticais, nas malhas de pesquisa $100 \times 100 \mathrm{~m}$ e $50 \times 50 \mathrm{~m}$, ao longo das direções norte-sul (NS) e leste-oeste $(\mathrm{EW})$ e de furos de perfuratriz de $8 \mathrm{~m}$ de profundidade, na malha $25 \times 25 \mathrm{~m}$, nas mesmas direções. A Figura 1 mostra as posições em planta do topo dos furos. Pode-se observar a localização preferencial das informações na porção sudoeste da área em estudo, região mais rica em hematita especular e onde estão concentradas as operações de lavra atualmente.

\section{Análise estatística e variabilidade espacial}

Para utilizar os dados de perfuratriz e de sonda conjuntamente e uma vez que os furos estão preferencialmente localizados em regiões mais ricas em $\mathrm{He}$, foi aplicada a técnica de remoção de agrupamentos pelo estabelecimento de diversos grids de teste, que permitiram a associação de um peso para cada amostra e posterior seleção do grid que conduza à menor média ("cell declustering", Isaaks \& Srivastava, 1989, p. 243). Os resultados obtidos são mostrados na Figura 2, na qual são fornecidos os histogramas da $\mathrm{He}$ em furos de sonda, de

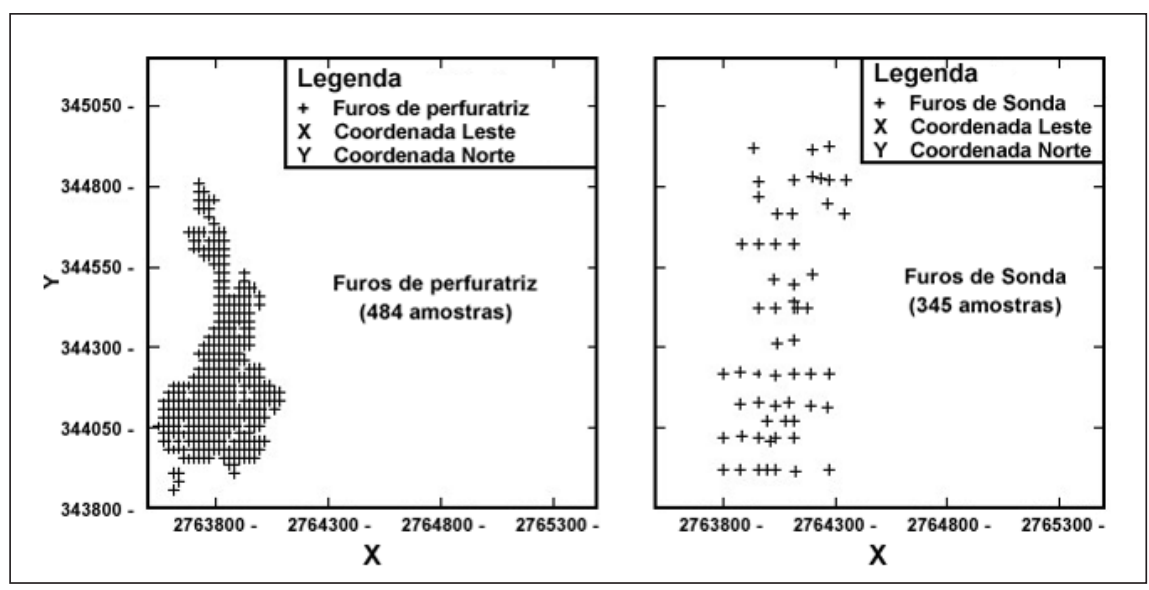

Figura 1 - Localização das informações.
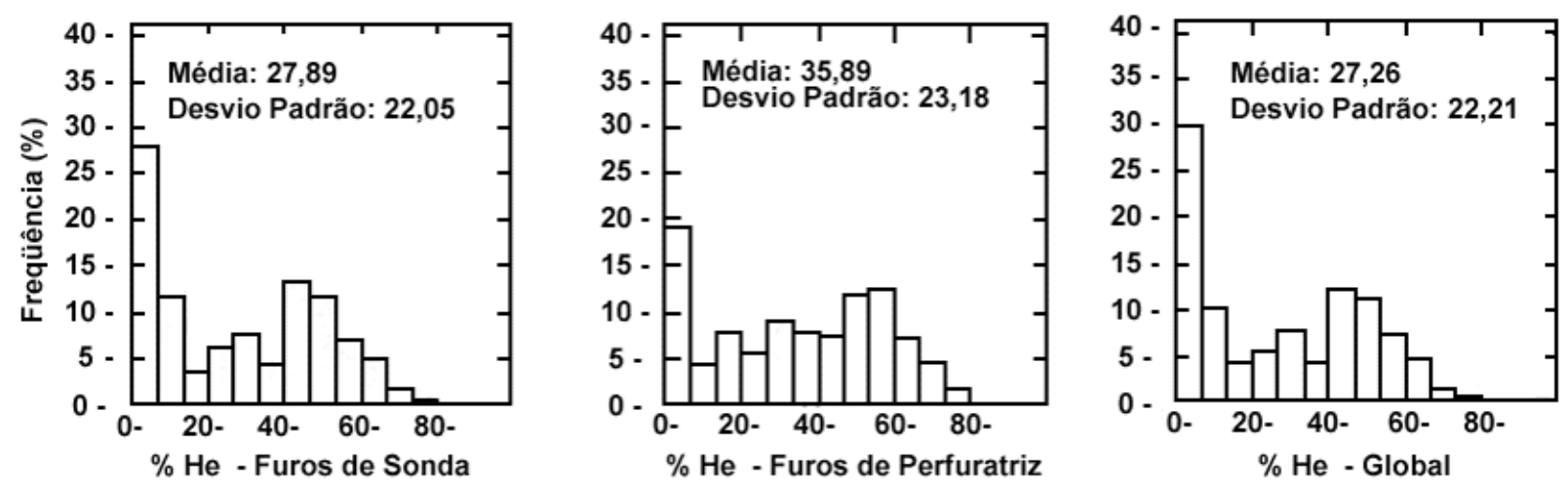

Figura 2 - Histogramas da hematita especular.

124 REM: R. Esc. Minas, Ouro Preto, 56(2): 123-129, abr. jun. 2003 
perfuratriz e o histograma conjunto da He global, representativo de toda a área em estudo.

Foram feitos variogramas experimentais nas direções NS, EW e vertical, definidas como principais. A direção NS é a direção de maior continuidade da variável He, sendo a direção vertical a de maior variabilidade. No ajuste, foi adotado o modelo esférico, cuja proximidade da origem é aproximadamente linear e com menor inclinação ao longo da direção NS, confirmando ser esta a direção de maior continuidade. A Figura 3 mostra a representação gráfica dos variogramas experimentais e dos modelos variográficos nas três direções principais. Nessa figura, os pontos representam o variograma experimental, as linha contínuas representam o modelo variográfico e as amplitudes são dadas em metros (m).

\section{Modelos de simula- ção e de estimativa geoestatística}

O método de simulação usado foi o de simulação seqüencial gaussiana (SSG), condicionada aos dados de He. Foram feitas 50 simulações, em um grid fino de dimensões 3,125 x 3,125 x 8m (dimensões dadas ao longo das direções NS, EW e vertical, respectivamente), para reproduzir a variável He a nível de suporte pontual, totalizando 469.824 nós simulados. A validação dos resultados obtidos, em termos de características estatísticas da simulação de He nos nós do grid de $3,125 \times 3,125 \times 8 \mathrm{~m}$, é mostrada nas Figuras 4 e 5 . A Figura 4 fornece a estatística básica de 3 realizações tomadas como exemplo e escolhidas aleatoriamente entre as 50 simulações (simula- ção 1 (S_01), 27 (S_27) e 44 (S_44), respectivamente). A Figura 5 mostra graficamente a média e o desvio-padrão de todas as simulações. Verifica-se que as simulações efetuadas reproduziram satisfatoriamente as características estatísticas e a forma da distribuição das porcentagens da He global.

A verificação da reprodutibilidade do modelo variográfico nas simulações está ilustrada na Figura 6, onde os variogramas experimentais de todas as realizações podem ser vistos sobrepostos, juntamente com o modelo variográfico e o variograma experimental construído sobre os dados amostrais. Os variogramas experimentais das simulações reproduziram razoavelmente o modelo variográfico proposto da He. O maior desvio em relação ao modelo variográfico na direção vertical, para distâncias superi-

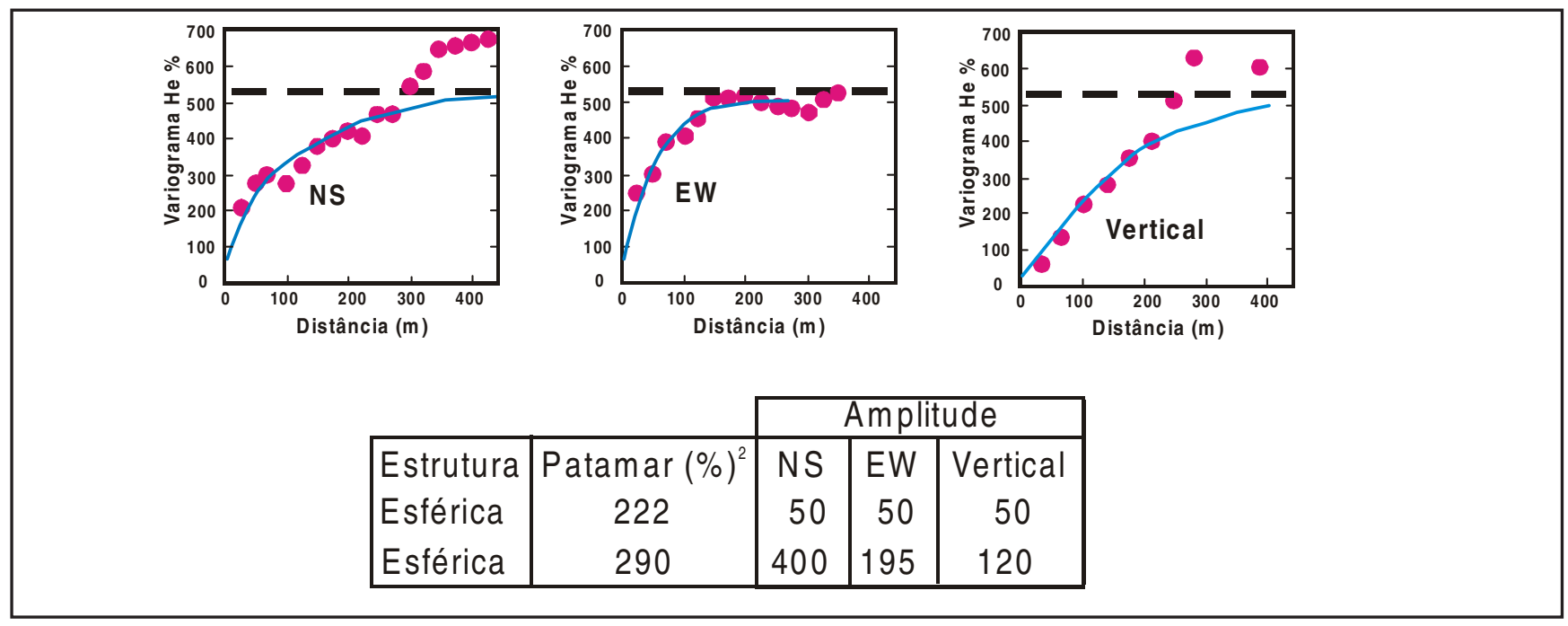

Figura 3 - Variogramas para He.

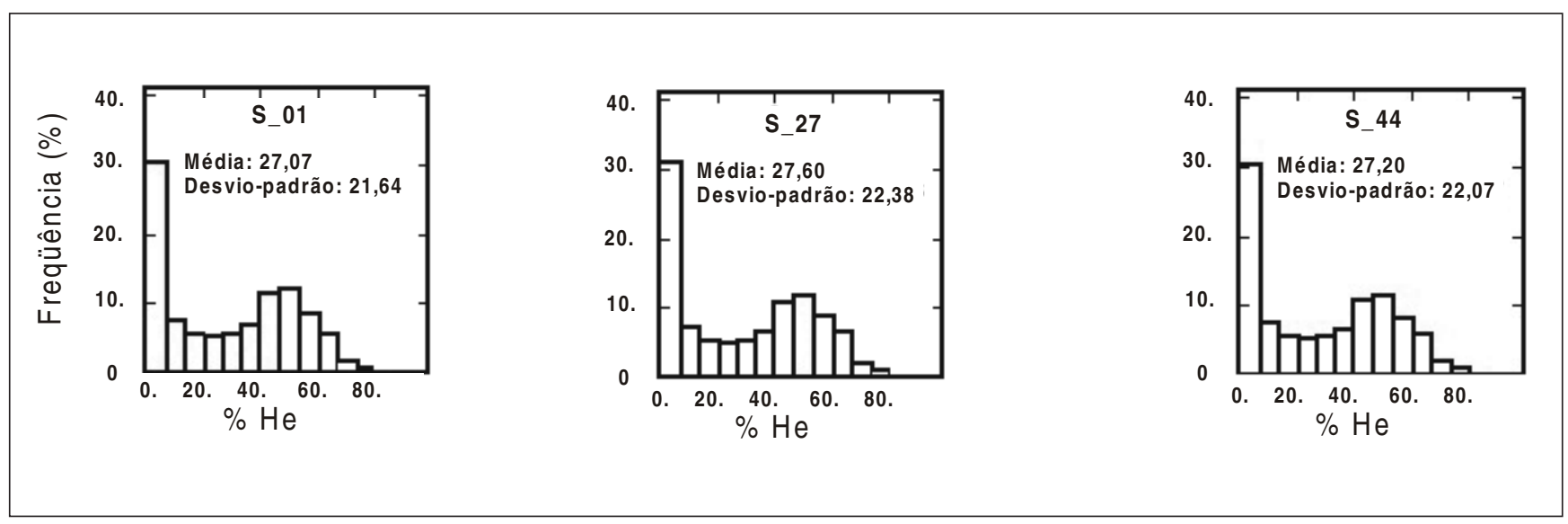

Figura 4 - Histogramas de 3 simulações. 
ores a 30m, não foi considerado como fator restritivo da validação da reprodutibilidade do modelo variográfico, já que o elipsóide de busca usado nas simulações foi limitado por um raio de $24 \mathrm{~m}$ na vertical, comprimento coincidente com a altura dos bancos operacionais de lavra.

Na implementação dos teores simulados de He nos blocos de lavra, a partir dos resultados das simulações nos nós do grid de 3,125 × 3,125 x 8m, utilizou-se um procedimento de mudança de suporte, no qual o valor de He simulado em um dado bloco de lavra equivale à média dos valores simulados dos nós interiores a esse bloco. A mudança de suporte foi feita para dois suportes de blocos, sendo o primeiro em 9788 blocos de 12,5 x 12,5 x 24 m e o segundo em 2447 blocos de 25 x 25 x 24 m (dimensões dadas ao longo das direções NS, EW e vertical, respectivamente). A escolha desses dois suportes distintos se deve ao fato de que, na SAMARCO, a malha de controle de pré-lavra é de 12,5 x 12,5m para variáveis químicas e de 25 x $25 \mathrm{~m}$ para variáveis mineralógicas. Assim, objetiva-se comparar os resultados da estimativa de reservas nos dois suportes referidos. Os resultados desse procedimento são mostrados na Tabela 1 , onde é feita também a comparação com os resultados de estimativas por krigagem nos blocos de lavra. Esses resultados refletem a ação combinada dos efeitos de suporte e de informação (Matheron, 1984, Rivoirard, 1987), além do efeito característico de atenuação da variabilidade real na krigagem (Journel \& Huijbregts, 1978), o que levou à redução da variabilidade dos blocos krigados, em relação às simulações.

Para enfatizar as diferenças entre os resultados obtidos em termos da distribuição espacial dos teores de $\mathrm{He}$, a Figura 7 fornece as imagens dos mapas da simulação 27 (S_27) e da krigagem em blocos de 12,5 x 12,5 x $24 \mathrm{~m}$ e 25 x 25 x $24 \mathrm{~m}$, respectivamente, em uma bancada operacional central de lavra (elevação 1.152).

Verifica-se que os teores nas imagens da krigagem estão mais atenuados, tendendo para a média de $\mathrm{He}$, ao passo que, nas imagens da simulação 27, valores extremos e descontinuidades locais de teores podem ser notados, sendo esse efeito mais pronunciado para os blocos de $12,5 \times 12,5 \times 24 \mathrm{~m}$.

\section{Determinação de teores de corte e estimativa de reservas}

Segundo Rivoirard (1994), o cálculo da reserva recuperável depende do estabelecimento das relações entre tonelagem e teor, as quais são obtidas por meio das chamadas funções de recuperação.

De posse dos resultados da krigagem e das simulações, foram feitas as curvas da função de recuperação $m(z)$, teor médio em função do teor de corte, para estipular um conjunto de teores de corte que garanta a especificação de He. Essas curvas são mostradas na Figura 8, onde os valores estão em porcentagens de He e a abreviatura SGS nas legendas

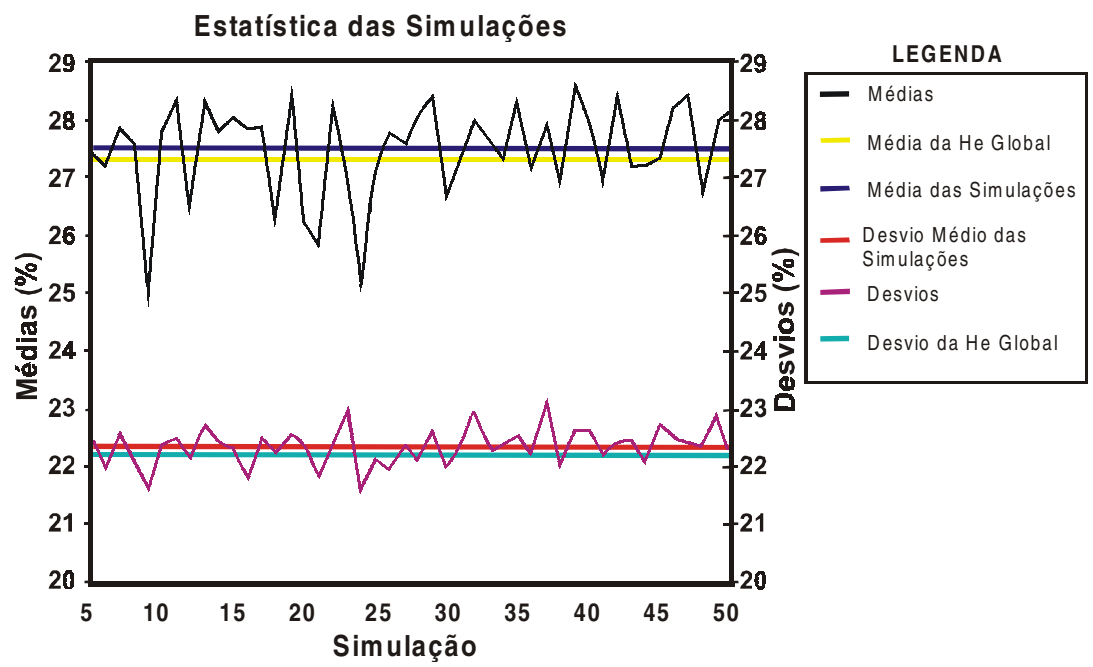

Figura 5 - Gráfico da estatística básica das simulações.

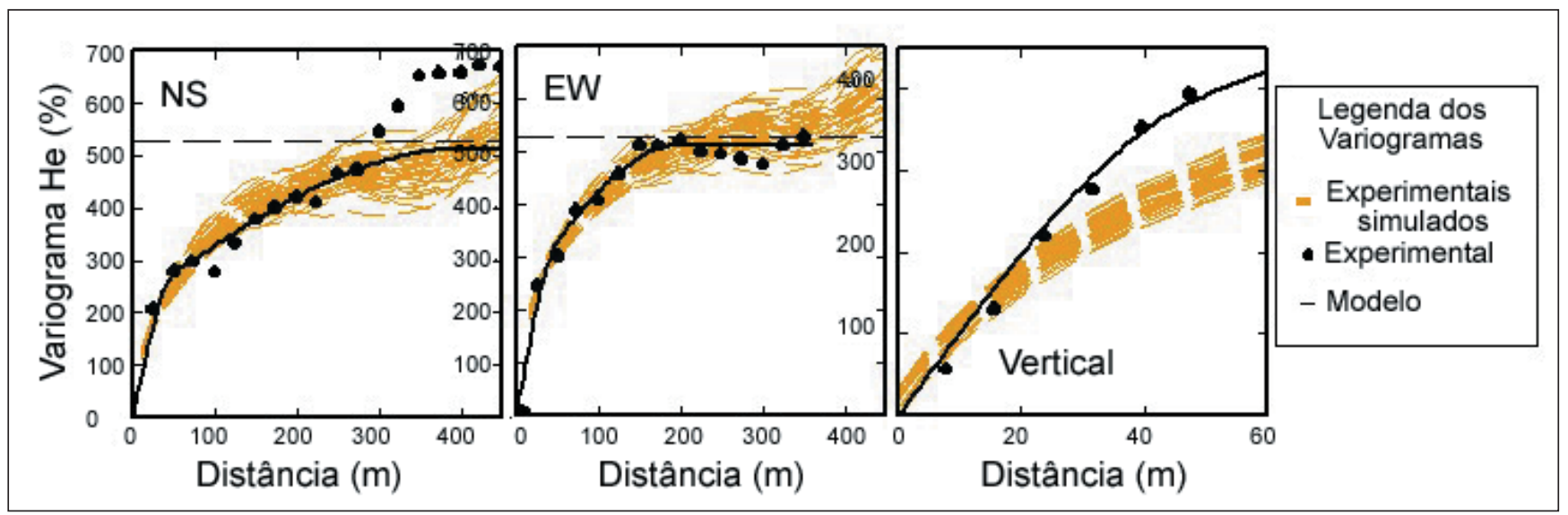

Figura 6 - Verificação da reprodução do modelo variográfico. 
tem o mesmo significado de SSG. Conforme citado anteriormente, o processo de lavra da SAMARCO tem de produzir minérios com teores médios de $47 \%$ de He. Assim, a partir das curvas da função $m(z)$, fixando-se o teor médio de $47 \%$ de He, obtêm-se 50 valores equiprováveis de teores de corte provenientes das simulações e um valor de teor de corte estimado por krigagem, para cada um dos suportes em análise.

A Figura 9 fornece o resumo estatístico dos 50 teores de corte das simulações, o valor do teor de corte estimado por krigagem, além dos histogramas das distribuições de teores de corte obtidos das simulações, para os dois suportes de blocos considerados. Nessa figura, os histogramas aparecem superpostos, para efeitos de comparação. Nessa figura, a sigla tc significa teor de corte e os valores estão em porcentagens de $\mathrm{He}$.

As curvas da função de recuperação $T(z)$, tonelagem de minério em função do teor de corte, são mostradas na Figura 10. Em todas as curvas, o valor de $T(z)$ tem o significado de reserva recuperável de minério de ferro, em termos de porcentagem da tonelagem total do recurso mineral disponível na região em estudo. Nesse estudo, a reserva recuperável depende somente do teor de corte $Z$ adotado (única restrição), admitindo, para simplificação, que a escolha de cada bloco é realizada independentemente de sua localização no depósito e de sua vizinhança.

A partir das curvas da função $T(z)$, ao se fixar cada um dos níveis de teores de corte das simulações mostrados na Figura 9, obtêm-se 50 valores equiprováveis de reservas com teor médio de $47 \%$ de He, para cada suporte de bloco considerado. A análise da variação das 50 reservas resultantes por teor de corte selecionado foi feita considerando-se os seus valores mínimos, médios e máximos. Os resultados desse procedimento são dados na Tabela 2, em porcentagens do recurso mineral total. Nessa tabela também são mostrados os dois valores de reservas obtidas da krigagem, resultantes da aplicação dos teores de corte krigados, sendo um valor para cada suporte. A representação gráfica dos resulta-

Tabela 1 - Resumo estatístico comparativo: Simulação e Krigagem.

\begin{tabular}{c|c|c|c|c}
\hline \multirow{2}{*}{$\begin{array}{c}\text { Resultados: \% He } \\
\text { Blocos de lavra }\end{array}$} & \multicolumn{2}{|c|}{ Blocos 12,5 x 12,5 x 24 } & \multicolumn{2}{c}{ Blocos 25 x 25 x 24 } \\
\cline { 2 - 5 } & Média & Desvio-padrão & Média & Desvio-padrão \\
\hline S_01 & 27,48 & 20,36 & 26,66 & 19,87 \\
\hline S_27 & 27,82 & 21,17 & 26,91 & 20,59 \\
\hline S_44 & 27,64 & 20,85 & 26,74 & 20,02 \\
\hline $\begin{array}{c}\text { Média das 50 } \\
\text { simulações }\end{array}$ & 27,80 & 21,24 & 29,95 & 20,58 \\
\hline Krigagem & 27,71 & 19,59 & 26,66 & 19,16 \\
\hline
\end{tabular}

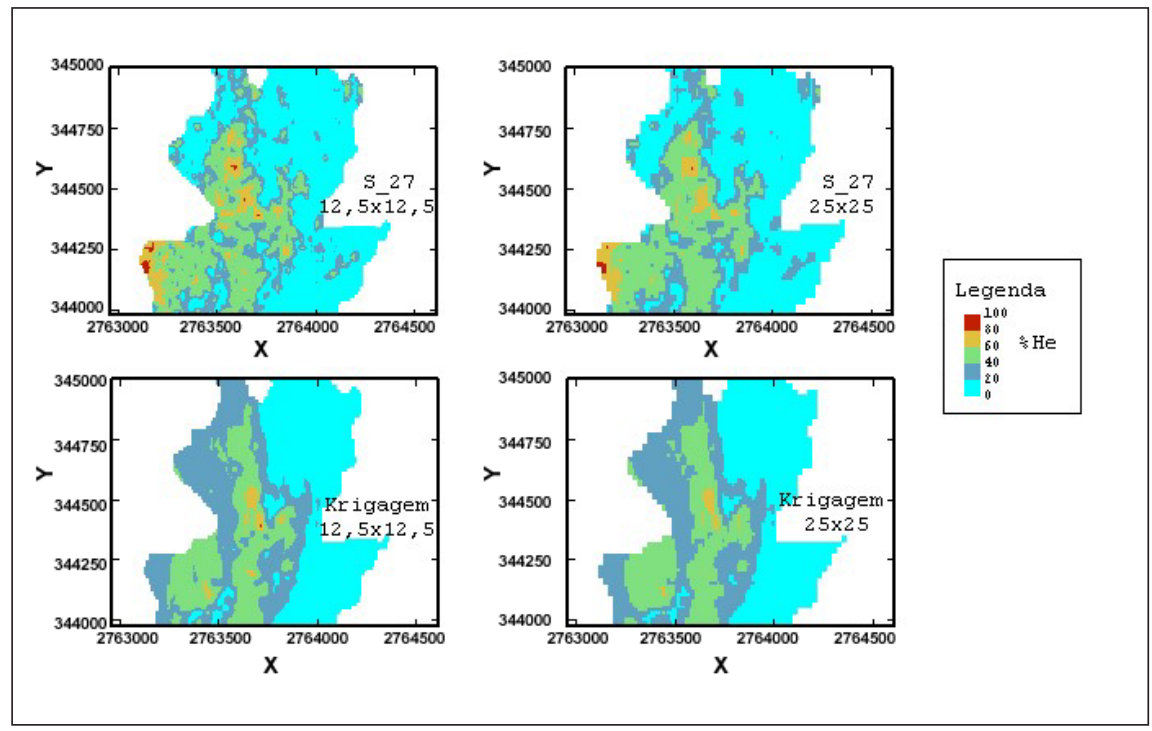

Figura 7 - Imagens da simulação 27 e da krigagem da He.
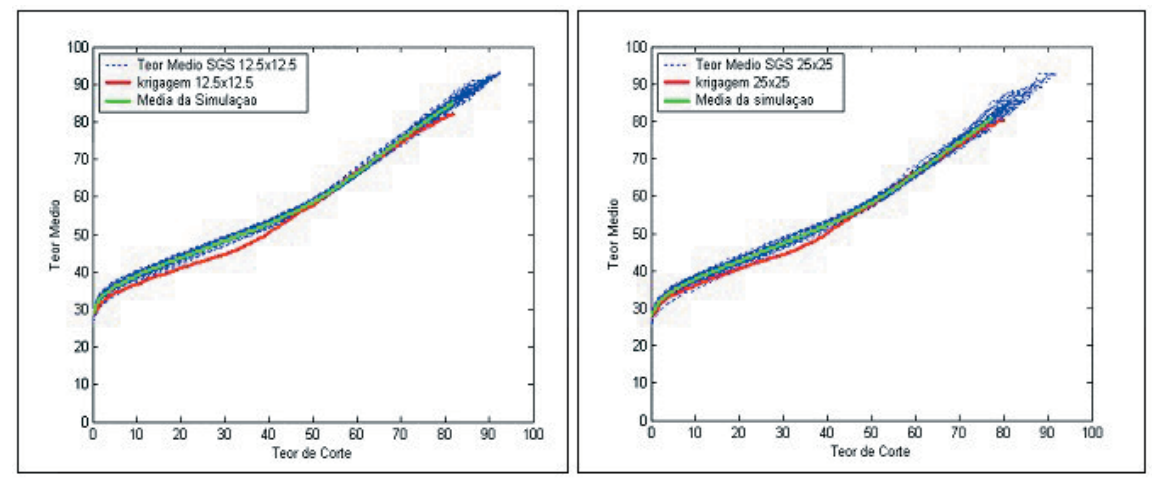

Figura 8 - Curvas da função $m(z)$.

dos da estimativa de reservas é mostrada através da Figura 11.

A análise da Tabela 2 e da Figura 11 permite afirmar que a seleção de reservas obtidas das simulações indicou ganhos de tonelagem em relação à seleção de reservas obtidas pela krigagem, para todos os teores de corte analisados. Seleção de reservas por blocos de $25 \times 25 \times 24 \mathrm{~m}$ projetou perdas de tonelagem em relação à seleção por blocos de $12,5 \times 12,5 \times 24 \mathrm{~m}$, tanto para o modelo estimado por krigagem quanto para o modelo de simulação. Esses resultados 


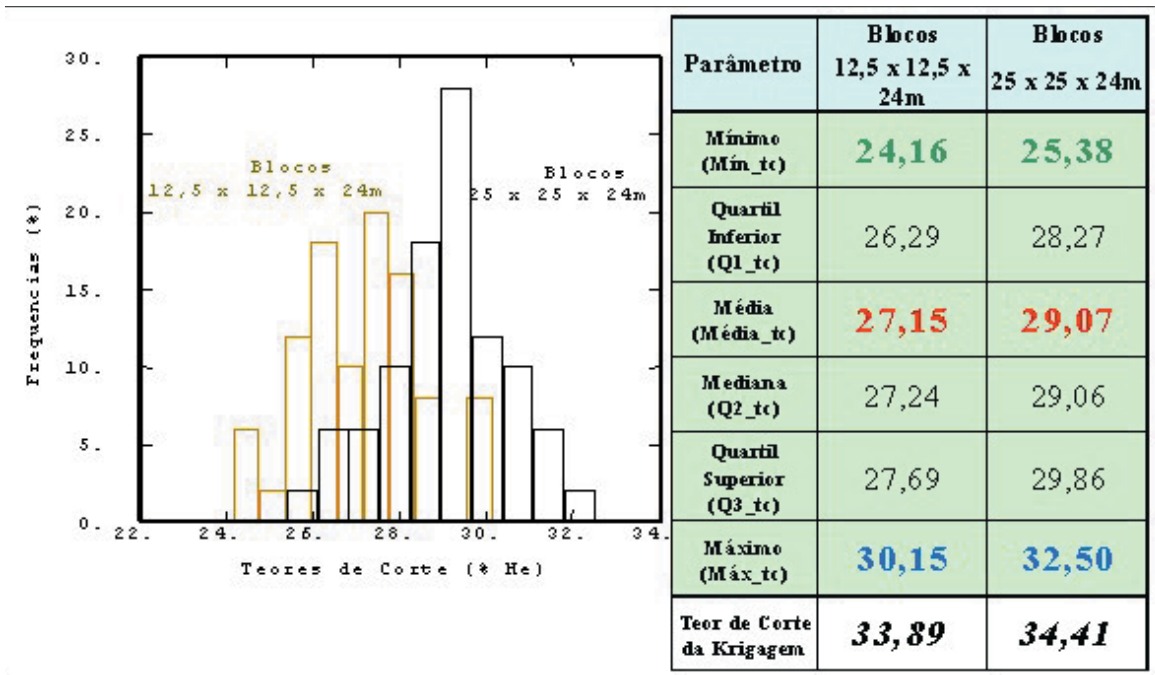

Figura 9 - Estatística dos teores de corte para obtenção de $47 \%$ de teor médio de He.
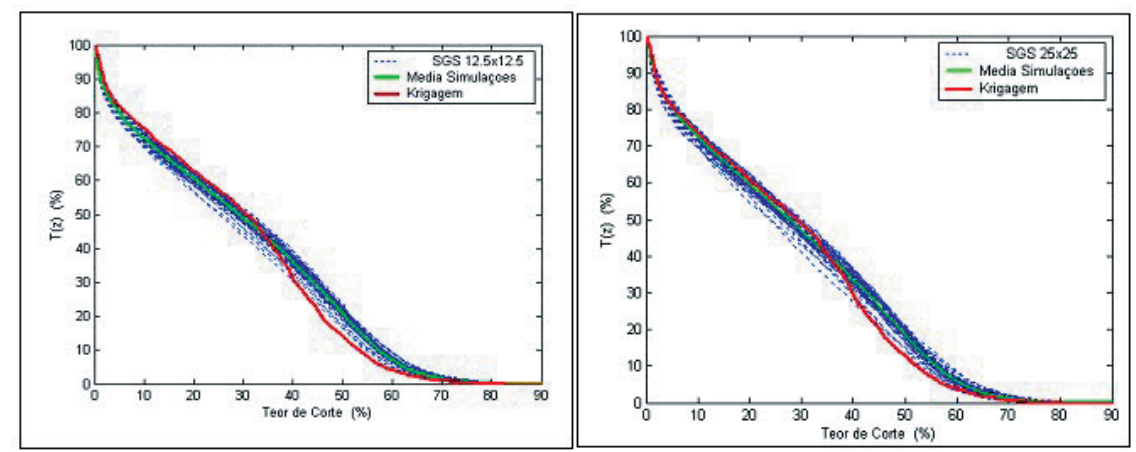

Figura 10 - Curvas da função $T(z)$.

Tabela 2 - Resultados da estimativa de reservas.

\begin{tabular}{|c|c|c|c|c|c|}
\hline Suporte & $\begin{array}{c}\text { Significado } \\
\text { dos teores de } \\
\text { corte (tc) }\end{array}$ & $\begin{array}{l}\text { Valor dos } \\
\text { tc }(\% \mathrm{He})\end{array}$ & $\begin{array}{c}\text { Reserva } \\
\text { mínima } \\
(\%)\end{array}$ & $\begin{array}{c}\text { Reserva } \\
\text { média } \\
(\%)\end{array}$ & $\begin{array}{c}\text { Reserva } \\
\text { máxima } \\
(\%)\end{array}$ \\
\hline \multirow{7}{*}{$\begin{array}{c}\text { Blocos } \\
12,5 \times 12,5 \\
\quad \times 24 \mathrm{~m}\end{array}$} & Mín_tc & 24,16 & 51,25 & 55,82 & 58,62 \\
\hline & Q1_tc & 26,29 & 48,36 & 53,35 & 56,15 \\
\hline & Média_tc & 27,15 & 47,19 & 52,33 & 55,26 \\
\hline & Q2_tc & 27,24 & 47,08 & 52,23 & 55,16 \\
\hline & Q3_tc & 27,69 & 46,53 & 51,70 & 54,59 \\
\hline & Máx_tc & 30,15 & 43,49 & 48,78 & 51,69 \\
\hline & Krigagem & 33,89 & \multicolumn{3}{|c|}{43,17} \\
\hline \multirow{7}{*}{$\begin{array}{l}\text { Blocos } 25 \\
\times 25 \times 24 m\end{array}$} & Mín_tc & 25,39 & 49,53 & 54,40 & 57,05 \\
\hline & Q1_tc & 28,27 & 45,82 & 51,02 & 53,88 \\
\hline & Média_tc & 29,07 & 44,83 & 50,08 & 52,92 \\
\hline & Q2_tc & 29,06 & 44,84 & 50,10 & 52,93 \\
\hline & Q3_tc & 29,86 & 43,87 & 49,12 & 52,01 \\
\hline & Máx_tc & 32,50 & 40,48 & 45,94 & 48,95 \\
\hline & Krigagem & 34,41 & \multicolumn{3}{|c|}{39,98} \\
\hline
\end{tabular}

sugerem a mudança da malha de controle de pré-lavra de hematita especular, da atual malha de $25 \mathrm{x} 25 \mathrm{~m}$ para uma malha de $12,5 \times 12,5 \mathrm{~m}$. Para definir a viabilidade de se mudar a malha de controle de prélavra da hematita especular, de $25 \times 25 \mathrm{~m}$ para $12,5 \times 12,5 \mathrm{~m}$, foi verificado se o aumento de custos proveniente da execução e das análises mineralógicas de um número maior de furos de perfuratriz pode ser compensado pela economia proporcionada através de remoção de tonelagens menores de estéril, no caso de se utilizarem blocos de 12,5 x 12,5 x 24m. De fato, para cada furo de perfuratriz da malha de 25 x $25 \mathrm{~m}$, haverá 4 furos correspondentes na malha de $12,5 \times 12,5 \mathrm{~m}$. Por outro lado, a seleção por blocos de 12,5 x $12,5 \times 24 \mathrm{~m}$ projetou reservas maiores em relação à seleção por blocos de $25 \mathrm{x}$ $25 \times 24 \mathrm{~m}$ e a diferença entre as reservas desses dois suportes, para cada nível de teor de corte, é igual à tonelagem de estéril adicional que seria gerada no caso de se utilizarem blocos de 25 × 25 × $24 \mathrm{~m}$. Uma vez calculado os custos específi$\cos \boldsymbol{C}_{25}$ (custo de execução e de análise mineralógica na malha de $25 \times 25 \mathrm{~m}$ ), $\boldsymbol{C}_{12}$ (custo projetado de execução e de análise mineralógica na malha de 12,5 x 12,5m) e $\boldsymbol{C} \boldsymbol{E}$ (custo de estéril), em unidades monetárias por porcentagem do recurso mineral total, para que seja compensatória a mudança da malha de controle de pré-lavra de 25 x $25 \mathrm{~m}$ para $12,5 \times 12,5 \mathrm{~m}$, deve-se obedecer à seguinte condição: $\boldsymbol{C E} /\left(\boldsymbol{C}_{12}-\boldsymbol{C}_{25}\right)>\mathbf{1}$, ou seja, o custo de remoção de estéril deve ser superior ao acréscimo de custo projetado para manter uma malha de pré-lavra mais fechada. Sabe-se que $C_{12}=4 C_{25}$ e, segundo dados informados pela SAMARCO, tem-se $C E=1923 C_{25}$. Assim, $C E /\left(C_{12}-C_{25}\right)=641$ e, dessa forma, a mudança de malha proposta é bastante compensatória. A economia futura advinda do uso da malha de 12,5 x 12,5m, em relação ao atual uso da malha de $25 \times 25 \mathrm{~m}$, pode ser obtida por: $\left(\boldsymbol{R}_{12}-\boldsymbol{R}_{25}\right) *\left(\boldsymbol{C E}-\left(\boldsymbol{C}_{12}-\boldsymbol{C}_{25}\right)\right)$

(em unidades monetárias), onde $\boldsymbol{R}_{12}$ e $\boldsymbol{R}_{25}$ são as reservas, em porcentagem do recurso mineral total, obtidas da seleção em blocos de 12,5 x 12,5 × 24 me de 25 × 25 $\mathrm{x} 24 \mathrm{~m}$, respectivamente. 


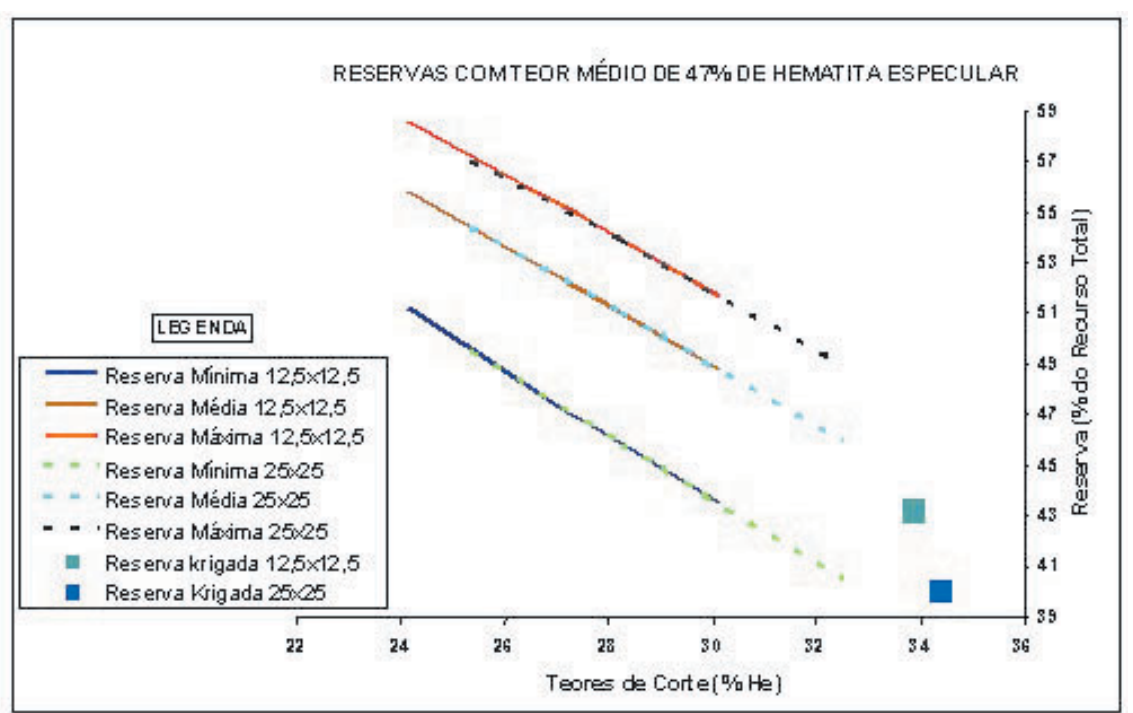

Figura 11 - Gráfico dos resultados da estimativa de reservas.

\section{Conclusões}

1. A simulação condicional pode reproduzir melhor a realidade dos teores em termos de sua variabilidade, distribuição espacial e continuidade. Dessa forma, obtiveram-se teores de corte que conduziram a estimativas de reservas que representam aproximações potenciais da reserva recuperável real desconhecida.

2. A característica de atenuação inerente à krigagem faz com que a variabilidade dos teores krigados de blocos fique reduzida em relação à variabilidade real. Dessa forma, obteve-se um teor de corte krigado que levou a uma estimativa conservadora de reservas, ou subestimação, em relação às estimativas obtidas pelas simulações, para ambos os suportes considerados.

3. Através dos modelos de simulação condicional implementados, foram es- tipulados dois conjuntos de teores de corte e de reservas equiprováveis, sendo um para cada suporte de bloco considerado. Em ambos os casos, os intervalos de variação das reservas representam a incerteza na quantificação das mesmas. O conhecimento desta incerteza vai suportar a tomada de decisão na escolha de um valor específico dentro do intervalo de teores de corte e a conseqüente determinação da reserva correspondente, em função do grau de tolerância ao risco, com o qual se queira trabalhar. No caso da krigagem, não é possível acessar essa incerteza, pois, para cada suporte de bloco, obtém-se uma única estimativa de reserva.

4. Os resultados obtidos mostraram que o aumento da seletividade da lavra, quando as dimensões do modelo de blocos são mudadas de 25 x 25 x $24 \mathrm{~m}$ para $12,5 \times 12,5 \times 24 \mathrm{~m}$, projetou ganhos de tonelagem de minério das reservas. Essas variações são provenientes da degradação diferenciada das curvas das funções de recuperação $m(z)$ e $T(z)$ nos dois suportes, explicadas pelos efeitos de suporte e de informação somados. Além disso, o custo do acréscimo do número de furos de perfuratriz e de análises mineralógicas, resultante da mudança da malha de controle lavra, de $25 \times 25 \mathrm{~m}$ para $12,5 \times 12,5 \mathrm{~m}$, foi amplamente compensado pela economia proporcionada através da redução da relação estéril / minério para blocos de 12,5 x 12,5 x 24 $\mathrm{m}$, o que validou o aumento da seletividade da lavra.

\section{Referências bibliográficas}

JOURNEL, A., HUIJBREGTS, C. J. Mining Geostatistics. New York: Academic Press, 1978.

MATHERON, G. The selectivity of the distributions and the second principle of geostatistics. In: GEOSTATISTICS FOR NATURAL RESOURCES CHARACTERIZATION, Lake Tahoe USA, D. Reidel Publishing Company, p. 421-433. 1984.

PEREIRA, W. C. Utilização de variável mineralógica na estimativa de reservas de minério de ferro. Campinas: Instituto de Geociências, UNICAMP, 2003. (Dissertação de Mestrado).

RIVOIRARD, J. Advanced geostatistics, fontainebleau, France: Centre de Géostatistique, École des Mines de Paris, (C131). 1987.

RIVOIRARD, J. Introduction to disjunctive kriging and non-linear geostatistics, Oxford, England: Oxford University Press, 1994. 180p.

\section{Artigo recebido em 01/04/2003 e aprovado em 10/06/2003.}
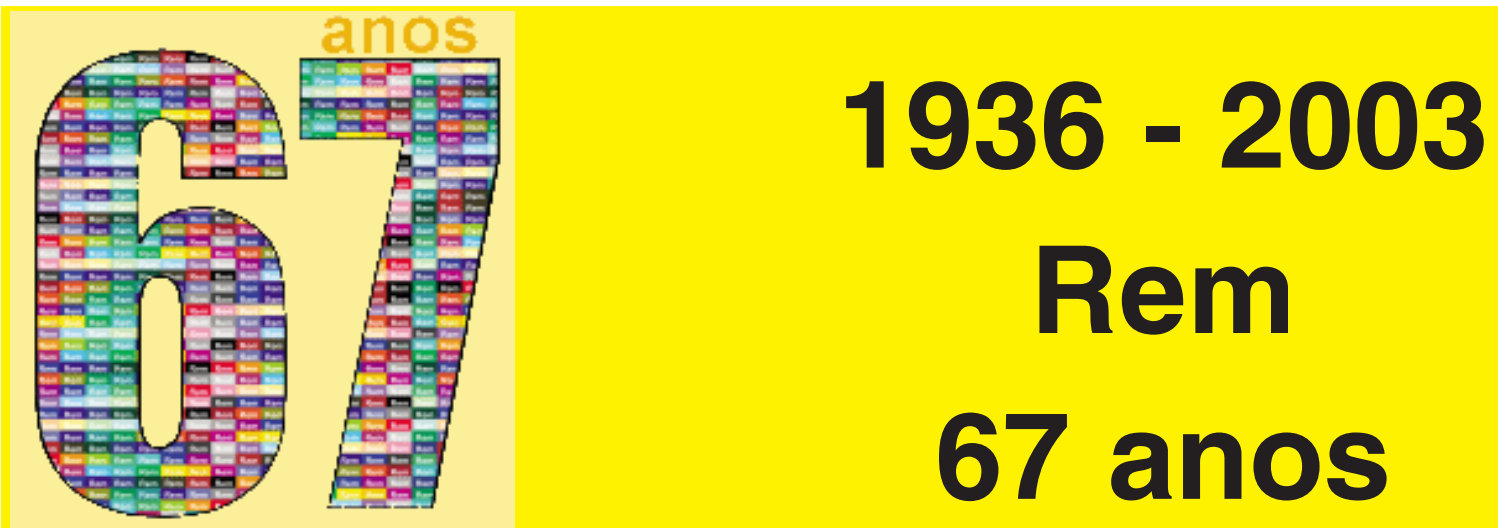

REM: R. Esc. Minas, Ouro Preto, 56(2): 123-129, abr. jun. 2003 